\title{
Who is violent?: factors associated with aggressive behaviors in Latin America and Spain
}

\author{
Pamela Orpinas ${ }^{1}$
}

ABSTRACT

The main purpose of this paper was to evaluate the strength of the association between: 1) aggressive behaviors and 2) attitudes and self-efficacy for alternatives to violence, in different cities of the Region of the Americas and Spain. Results were based on a cross-sectional household survey of a sample of the population aged 18 to 70 years. The survey was conducted in eight metropolitan areas of Latin America and Spain: Rio de Janeiro, Brazil; Salvador, Bahia, Brazil; Santiago, Chile; Cali, Colombia; San José, Costa Rica; San Salvador, El Salvador; Caracas, Venezuela; and Madrid, Spain. Each sample of approximately 1200 respondents per city was stratified by clusters and was proportional in terms of socioeconomic position and population density. In all cities and for all targets of aggression studied, people who reported using aggression were less likely to feel confident that they could solve conflicts without violence, and they were more likely to hold attitudes supporting violence. Young persons were also more likely to commit aggression against all the targets. In addition, aggression toward nonfamily members was found most frequently among young men who reported binge drinking, who either carried a firearm or would have liked to carry one, or who perceived the police as inefficient. Additional studies need to be done in each country to describe more specific attitudes associated with aggression within each subculture. Future prevention programs should focus on modifying attitudes that support violence, increasing self-efficacy in solving problems without using violence, supporting the development of a police system that people can trust, regulating firearms and access to alcohol, and raising people's education levels.

In the Region of the Americas, violence has been a source of concern among governmental and nongovernmental organizations and other social sectors. In addition, in recent polls, residents of large cities have defined violence as a major source of worry. Violence is one of the greatest threats to public health and security, causing injury, disability, and numerous premature deaths.

\footnotetext{
University of Georgia, Department of Health Promotion and Behavior. Mailing address: 300 River Road, Athens, GA 30602, United States of America. Phone: (706) 542-4370; fax: (706) 542-4956; e-mail: porpinas@coe.uga.edu
}

Only recently has the problem of violence been seen through the eyes of public health (1). Professionals in multiple disciplines have turned to public health as a method to reduce and prevent violence. This public health approach to solving health problems includes four steps: defining the problem, identifying risk factors, developing and evaluating interventions in defined populations, and applying proven strategies to the whole community (2). With its use of an epidemiologic model, public health assumes that the majority of violence does not occur by chance, that violence has causal factors that can be identified and prevented, and that these factors can vary among different populations and places.

In Latin America, a serious limitation to developing interventions to prevent violence has been the lack of information to clearly define the problem among different social groups and to identify risk factors associated with the acquisition, maintenance, and enactment of violence. With the objective of identifying cultural risk factors associated with violence that could be used to guide policies and develop prevention programs, the Pan American Health Organization (PAHO) undertook the ACTIVA project (Estudio 
Multicéntrico sobre Actitudes y Normas Culturales frente a la Violencia en Ciudades Seleccionadas de América Latina y España, or Multicenter Study: Cultural Norms and Attitudes Toward Violence in Selected Cities of Latin America and Spain). ACTIVA is a comparative study of cultural norms and attitudes associated with aggressive behaviors toward children, the partner, and persons outside the family, in different cities of the Region of the Americas and Spain.

Multiple risk factors are associated with violence. This paper focuses on attitudes and self-efficacy, two risk factors that can influence whether or not a person will choose to behave aggressively. Attitudes can be used as a proxy to measure cultural values. Culture has been described as the milieu of attitudes and values that affects all choices (3). Comparisons across countries will yield information to understand the relative importance of these risk factors. Measuring attitudes will give a better understanding of cultural support for aggression.

In this study, aggressive behaviors toward three targets were used as the dependent variable: aggression toward children in the form of corporal punishment, aggression toward the partner, and aggression toward nonfamily members. Aggression toward children by parents and caretakers in the form of corporal punishment is of special concern, due to its high prevalence and its longlasting, deleterious effects. Corporal punishment is defined as the infliction of physical pain on a child or adolescent by a caretaker, with the purpose of modifying a behavior that the caretaker perceives as undesirable. It includes such behaviors as spanking, slapping, grabbing, shoving, or hitting with objects (4). About $80 \%$ of the parents in the United States of America spank their children (5), and a similarly high prevalence was found in Costa Rica (6).

The long-term consequences of corporal punishment are of concern. Abusive disciplinary methods of children are strong predictors of adolescent and adult violence (7) and of male delinquency (8). Physical punishment dur- ing childhood is a risk factor for depression, hopelessness, alcohol abuse, suicide, violence against peers, physical abuse of one's own children, and physical assaults on partners $(5,9,10)$. In addition, corporal punishment does not correct antisocial behavior. In fact, longitudinal studies have shown that spanking increases the likelihood of antisocial behavior (11). PAHO has already started a regional effort to reduce corporal punishment (12).

Aggression toward the partner is the second dependent variable of this study. Of special concern is the violence males commit against female partners. Cross-cultural research has shown that violence against women is an integral part of virtually all cultures. A review of 35 prevalence studies in industrial and developing countries showed that one-quarter to more than one-half of the women reported having been physically abused by a male partner. Although some studies were based on convenience samples, most were based on probability samples with large numbers of respondents (13). In a review of the literature in the United States, Plichta (14) found that the prevalence of men abusing a female partner ranged between $10 \%$ and $35 \%$, and that rates of severe abuse ranged between $6 \%$ and $11 \%$. It is not possible to obtain one measure of prevalence of abuse. Studies that assess abuse may be individually valid but they are not directly comparable because they use different questions to evaluate abuse, have different time frames, or use different methods to collect the data. For example, percentages of women reporting being physically abused can range widely: $4 \%$ and $6 \%$ using a mailed questionnaire (15), 7\% using a selfreported questionnaire filled in at the clinic (16), and $26 \%$ using a personal interview (17). Finally, experts agree that violence against women is largely underreported.

Aggression toward nonfamily members is the third dependent variable of this study. In the United States, it was estimated that over 9 million people were assaulted in 1994. Strangers or casual acquaintances committed twothirds of these assaults. Both victims and perpetrators were more likely to be young males. Assaults were most frequent in urban areas and among people of low income (18).

The risk factors selected for this study were attitudes toward the environment, attitudes toward specific behaviors, self-efficacy, carrying a firearm, binge drinking, and the three demographic variables of gender, age, and education. Attitudes are defined as a "relatively constant feeling, predisposition, or set of beliefs directed toward an object, person or situation" (19). Perceived self-efficacy is defined as "a judgement of one's capabilities to accomplish a certain level of performance" (20, p. 391).

Identifying factors that predict or regulate aggression could provide guidance for intervention strategies and government policies. In the ACTIVA project, the selection of determinants of aggressive behaviors was based on social cognitive theory. According to this theory, factors in the environment where the person lives, personal factors (e.g., attitudes, self-efficacy, etc.), and other behaviors associated with aggression influence and determine each other (20). The specific risk factors for violence can also be organized into three broad phases: 1) the acquisition phase, consisting of early predictors of aggression and factors associated with the learning process of aggression, 2) the maintenance phase, consisting of personal and environmental factors associated with how aggression is maintained over time, and 3) the performance phase, consisting of factors that instigate or facilitate aggression in the moment it is performed (21).

To understand the influence of the environment, it is important to differentiate between the real and perceived environment. The environment will influence people more strongly according to their perception of the environment than according to its actual conditions (20). Thus, in this study, the environment was measured through individual attitudes toward aspects of the environment, which do not necessarily reflect the "real" environment.

The environment influences aggression through several mechanisms. The 
environment provides the opportunity for violence to be observed and learned, both through the observation of real persons who behave aggressively and through the observation of models in the mass media $(20,22)$.

Developing aggressive behaviors is also influenced by cultural norms that accept and promote violence (23). An important aspect of these norms is the justification of illegal acts, under the assumption that aggressive people, or people who live in communities that accept aggression as a way to solve conflicts, will tend to justify illegality more than will persons who are less aggressive.

The environment also provides legal mechanisms to control and punish aggression. Several of the ACTIVA survey questions evaluated the subjective perception of social institutions, which does not necessarily reflect the actual conditions of the institutions but how they are perceived and, therefore, how people will act toward them. The hypothesis to be evaluated is that people who trust the social institutions that control violence (such as the police) will be less likely to take justice into their own hands and, therefore, would be less aggressive. People who do not trust the police or the legal system would prefer personal vengeance rather than looking for a legal solution.

The environment also provides a wide range of rewards and punishments, as well as the availability of alternative means of securing goals, which influence whether or not people will behave aggressively under given circumstances. Social cognitive theory distinguishes three forms of reinforcement that control aggression: external reinforcement, vicarious or observed reinforcement, and self-reinforcement. People receive external reinforcement for their aggressive behaviors in a variety of ways. For example, thieves obtain money or possessions, aggressive persons may increase their status, and aggressors receive attention. By observing others, we learn what behavior is rewarded, ignored, or punished. Observed rewards increase the tendency to behave like the model, and observed punishments decrease this tendency. The absence of anticipated punishment conveys permissiveness and reduces fear; thus, behavioral restraints are reduced and aggressive actions are performed more readily. People also regulate their actions to some extent by self-produced consequences. People learn to evaluate their own behavior partly on the basis of how others have reacted to it. Parents and other socialization agents describe norms of what is worthy and what is reprehensible. Parents give their children approval when they meet moral standards and reprimand them when they do not meet these standards. As a result, children come to respond to their own actions with self-approval or selfcriticism. Systems of self-reinforcement can also be transmitted through modeling $(20,21)$.

Finally, structural violence, an aspect of the environment not directly addressed in this study, includes economic and social inequality, racism and other forms of discrimination, police brutality, corruption of the legal system and government, violation of human rights, and unequal access to education and jobs (24).

Attitudes toward some specific behaviors, as well as self-efficacy, are associated with aggression. To increase their predictive power, both attitudes and self-efficacy should be measured specifically. Attitudes toward such specific behaviors as insulting, hitting, or killing someone in a specific situation will be more strongly associated with behavior than more-general attitudes (25). For example, a specific attitude toward killing in a particular situation, such as "It is OK to kill the rapist of my daughter," should be more predictive of behavior than a general attitude toward killing, such as "It is OK to kill."

Several studies have shown that aggressive adolescents have stronger attitudes and beliefs supporting violence as a way to solve conflicts and have less ability to solve conflicts in nonviolent ways than do nonaggressive adolescents (23, 26-29). Perry, Perry, and Rasmussen (30) found a significant difference between aggressive and nonaggressive children in self-efficacy for aggression and for inhibition of ag- gression. Aggressive children reported that it is easier to perform aggression and more difficult to inhibit aggressive impulses, and these children were also more confident that their aggression would produce tangible rewards.

While biological and genetic risk factors are associated with aggression, they were not included in the ACTIVA project. These factors include attention deficit hyperactivity disorder, learning disabilities, poor motor-skill development, prenatal and perinatal complications, minor physical anomalies, head injury, and parental criminality $(31,32)$.

Violence is not an isolated event in people's lives. Other behaviors, such as carrying a weapon, alcohol abuse, and negative arguments or verbal insults, are also risk factors for violence, since they facilitate the performance of aggressive behaviors. Two of these risk factors were included in this study, weapon carrying and binge drinking. Weapon carrying or having easy access to weapons is a strong predictor of violence (33-35). The primary basis for the extremely high death rate from firearms is the lethality of the weapons rather than the characteristics of the people who kill or are killed (36). Alcohol and drugs are also a major risk factor for being the victim or the perpetrator of violence $(37,38)$. Weapon carrying, alcohol consumption, and arguments facilitate aggression. Arguments are the precipitating factor in one-third to one-half of all homicides, especially among teenagers and young adults $(36,39)$. Most homicides are committed with a firearm, occur during an argument, and occur among people who are acquainted with one another (40).

Demographic variables define the groups at highest risk for aggression. Prevalence studies of homicide, fighting, and other direct forms of aggression have shown that men are more aggressive than women (41-44), young people are more aggressive than older people, and people who belong to minority groups are more aggressive than people who belong to the majority (18). Violence disproportionally affects the poor and the uneducated. Crime rates are higher in low socioeconomic neigh- 
borhoods, and the risk of being the victim of crime increases for people of low socioeconomic status $(7,18)$.

The main purpose of this paper was to evaluate the strength of the association between: 1) attitudes and selfefficacy for alternatives to violence and 2) aggressive behaviors, in different cities of the Region of the Americas and Spain. Attitudes toward specific behaviors and attitudes toward the environment were evaluated. Also evaluated were the additional effects of two violence-related behaviors that can facilitate aggression, carrying a firearm and binge drinking. The hypothesis to be evaluated is that people who have attitudes that support violence, who have low self-efficacy for alternatives to violence, who have drunk excessive amounts of alcohol, and who carry or would like to carry firearms will show higher levels of aggression.

\section{METHODOLOGY}

The ACTIVA project used a crosssectional design to survey a sample of the population between 18 and 70 years old living in the selected cities. The survey was administered faceto-face in the participant's residence, in eight metropolitan areas of Latin America and Spain. Between July 1996 and March 1997, a representative sample was selected in each city by socioeconomic stratum, using a multistage sampling procedure. The sample was stratified by clusters and was proportional in terms of socioeconomic condition and population density. The sample size was estimated at 1200 individuals per city. Individuals were selected in households by systematic sampling without substitution. Data were collected using the same questionnaire in all eight cities.

The survey was administered to a sample of adults of eight cities: Salvador, Bahia, Brazil ( $n=1384)$; Rio de Janeiro, Brazil $(n=1114)$; Santiago, Chile ( $n=1212)$; Cali, Colombia $(n=$ $2288) ;$ San José, Costa Rica $(n=1131)$; San Salvador, El Salvador $(n=1290)$; Caracas, Venezuela ( $n=1297)$; and Madrid, Spain $(n=1105)$. The total sample for these eight cities was 10821 persons. Due to differences in sampling methods, in two cities, Santiago and Cali, the sample had to be adjusted for socioeconomic status and gender so that the sample would represent the distribution of the population. The definitions of socioeconomic status by city, as well as a detailed description of the methodology, are discussed in detail elsewhere in this journal issue (45). In all cities, women were slightly overrepresented. A total of 4736 men $(43.8 \%)$ and 6085 women $(56.2 \%)$ were surveyed (Table 1$)$. In most cities approximately $50 \%$ of the sample was obtained from areas defined as low socioeconomic status. Nonresponse rates were highest in the high socioeconomic stratum and lowest in the low stratum.

Working together, the principal investigators of each of the cities developed one common survey, with technical support from the Pan American Health Organization and the World Health Organization Collaborating Center at the University of TexasHouston. The final questionnaire included a wide range of sociodemo-

TABLE 1. Demographic characteristics of the sample by city, ACTIVA project, 1997

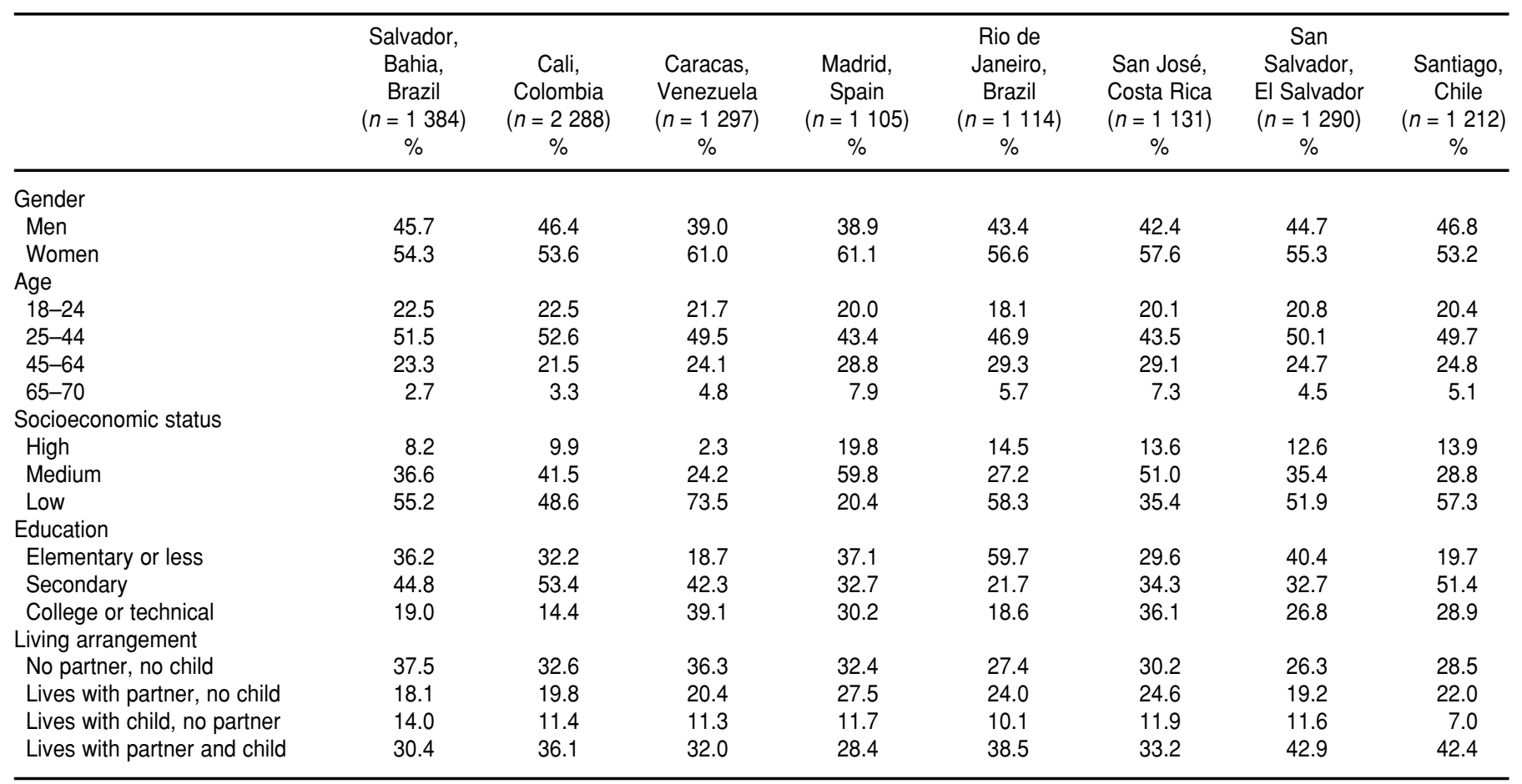


graphic characteristics of the interviewees and their families, prevalence of aggressive behaviors and of other violence-related behaviors, personal attitudes toward aggressive behaviors, self-efficacy for alternatives to violence, perception of the government and other social institutions, and victimization both in the family and in the community.

The three dependent variables of this study were physical aggression against nonfamily members, against the partner, and against one's children. Three questions measuring different levels of aggression were used to evaluate the frequency of aggressive behaviors against each of these target groups. Aggression against nonfamily members was measured by the following three items: insulted in connection with some problem, threatened to seriously harm, and assaulted or hit a nonfamily member. Aggression against the partner was measured by the following three items: shouted in anger, struck or slapped, and struck with an object that could have hurt the partner. Aggression against children was measured by the following three items: shouted at the child, spanked the child, and hit the child somewhere on the body other than the buttocks with an object such as a strap or a stick. The time frame for aggression against nonfamily members and the partner was the prior year, and possible responses ranged from 0 to 6 or more times. The time frame for aggression against children was the prior month and possible responses were "never," "less than 4 times in the month," "1-2 times per week," and "3 or more times per week." The questions of corporal punishment were limited to children from 2 to 15 years of age, and included parents and other caretakers. Questions were based on Straus's Conflict Tactics Scales (46).

To evaluate attitudes and self-efficacy, seven scales were created. All scales were composed of summated items divided by the total number of items, with possible scores ranging from 1 to 5 . Higher scores represented a stronger support for aggression and lower self-efficacy for alternatives to violence. The specific items of each scale and the internal consistency of the scores, measured by Cronbach's alpha, are presented in Table 2. While the items were developed specifically for the ACTIVA project, many of them were based on previous national surveys, polls, and research studies (45).

Five scales and one item measured attitudes toward these specific behaviors: killing others, slapping the partner, hitting the partner because of unfaithfulness (or hitting a woman who is "stealing the husband"), having a firearm to increase security, accepting some illegal behaviors, and corporal punishment as being necessary to bring up children properly (five scales shown in Table 2).

One scale and four items measured attitudes toward the environment. The scale was a measure of social intolerance, that is, whether neighborhoods should be composed of persons of similar social class, religion, ethnic group, and political ideas (Table 2). One of the items evaluated respondents' perception of the efficiency of the police, on a 5-point Likert-type scale ranging between "very good" and "very bad." The second item evaluated perceptions of democracy. Respondents chose among three alternatives: "democracy is the best political system under any circumstances," "in certain circumstances a dictatorship could be good," and "whether we live in a democracy or in a dictatorship makes no difference to people like me." The third item was a question measuring beliefs about how conditions in the country would be in the next five years. Possible alternatives were "better off than now," "as well off as now," and "worse off than now." The final question measured their perception of current conditions in the country. Possible alternatives were "the social system should be kept as it is," "some reforms should be made," and "the system should be totally changed."

Self-efficacy for alternatives to violence was measured by one scale, which combined three items: "when there is a problem, I know how to control my temper and stay out of fights," "if I have a serious conflict or disagreement with my partner, I can explain my reasons without getting upset," and "if I need to correct a child, I know how to talk or reason with them and explain why some of the things that they do are wrong." All items were measured on a 5-point Likert-type scale ranging from "always" to "never." The scale was composed of summated items divided by the total number of items, with possible scores ranging from 1 to 5 . Higher scores represented a lower self-efficacy for alternatives to violence.

Binge drinking was measured by one question from the U.S. Centers for Disease Control and Prevention's Behavioral Risk Factor Surveillance System (47). The question measures the frequency of drinking five or more alcoholic beverages on one occasion during the month prior to the survey. Responses could range from 0 to 10 or more times.

Firearm carrying was measured by several questions that were organized into three categories: does not have or want to have a firearm, does not have a firearm but would like to have one, and has a firearm for sport, profession, or personal protection.

Finally, three demographic variables were included in the model: gender, age, and education. Age was measured as a continuous variable. Education was organized into three levels: elementary education or less, high school education (complete or incomplete), and some college or technical education.

To evaluate whether physical aggression against one target group (child, partner, or nonfamily member) was associated with physical aggression against a different target group, odds ratios (OR) and the $95 \%$ confidence intervals (CI) were calculated. The OR represents an estimate of the odds of hitting someone, given that the person had hit someone from a different target group. Given that not all respondents had a partner or took care of a child, these analyses were based on the subsamples that reported taking care of a child between 2 and 15 years of age and/or having a partner, 
TABLE 2. Scale items and reliability coefficients by city, ACTIVA project, 1997

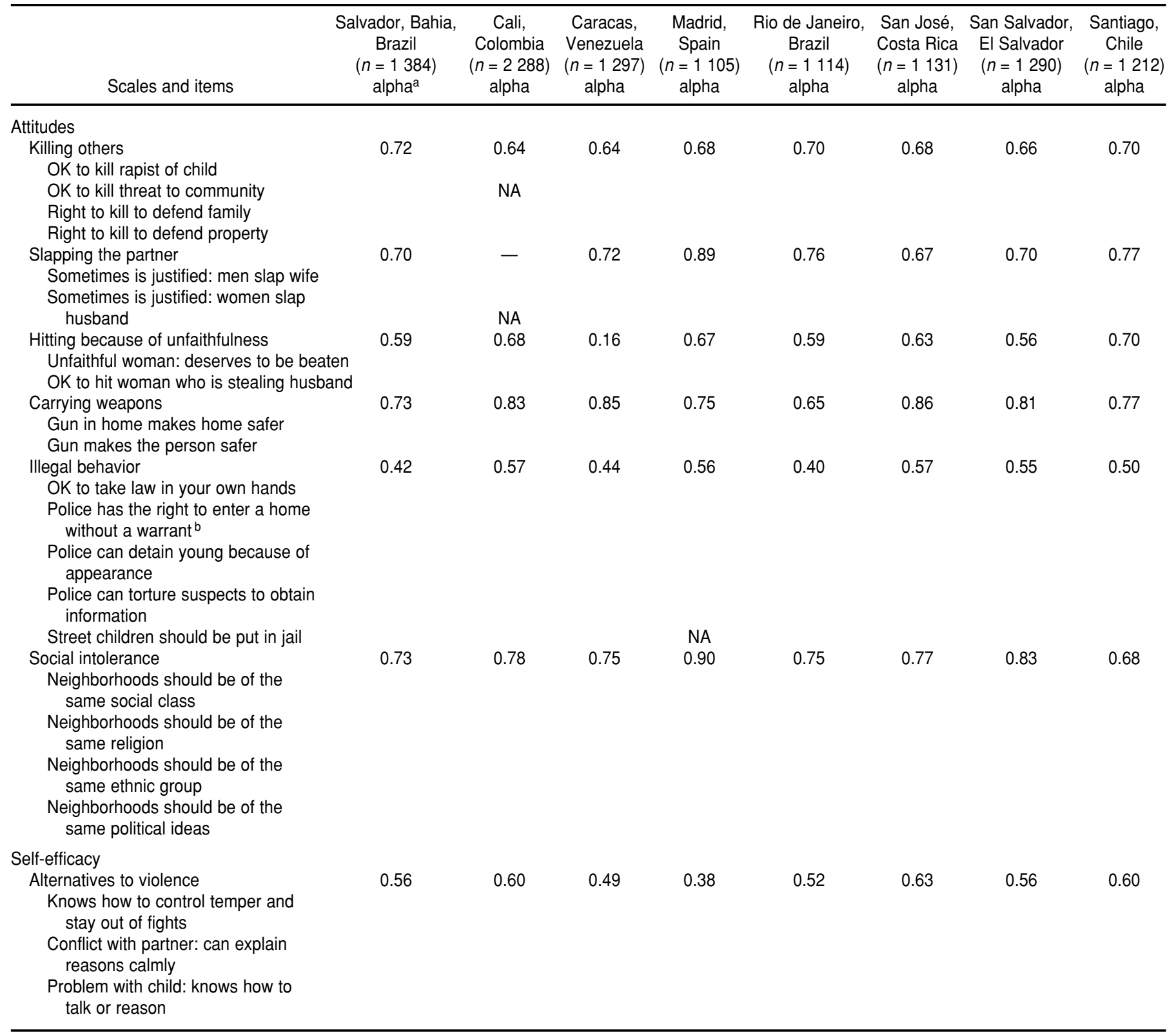

$\mathrm{NA}=$ Not available, item was not included in the survey.

${ }^{\text {a }}$ Cronbach's alpha.

b This item was not included in Caracas because alpha coefficient decreased to 0.32 .

depending on the analyses. Approximately one-third of the sample respondents reported both taking care of a child and having a partner, and another third reported not having a partner or a child (Table 1 ).

The prevalence of physically aggressive behaviors was described by type of physical aggression, target of the aggression, and city. In addition, fre- quency of aggressive behaviors was described by demographic characteristics of the sample, binge drinking, firearm carrying, perceived efficiency of the police, support for democracy, perception of the future of the country, and whether a person would like to change the social system. Chi-square was computed to evaluate bivariate association between categorical vari- ables. In addition, on all seven scales, analysis of variance was used to compare mean scores of those who hit someone versus those who did not hit, as well as support for corporal punishment. Frequencies and means were described by target of the aggression and by city.

Finally, the predictive power of the model was examined using linear re- 
gression. All analyses were done separately for each city and for each target of aggressive behavior. Variables were entered in three blocks. The first block was composed of attitudes toward the behaviors, attitudes toward the environment, and self-efficacy. The item evaluating democracy was dichotomized into "democracy is the best system" (lower value) versus all others. The item evaluating the current conditions of the country was dichotomized into "the system should be totally changed" (higher value) versus all others. In the second block, binge drinking and firearm carrying were added. Binge drinking was recoded so that codes would reflect the mid points of the range of the possible response (e.g., "never" was coded as " 0, ," " 1 to 2 times" was coded as " 1.5, ," etc.). Two dummy variables were created for firearm carrying: "carried a firearm" versus all other and "would like to carry a firearm" versus all other. The default was "does not have a firearm nor would like to have one." In the third block, the demographic variables were added. The final standardized beta weights were described for each city, allowing comparison of the relative importance of each variable for each city. The percentage of the variance explained for each additional block was also described.

For the dependent variables of the regression analyses, base 10 logarithmic scales were developed to reduce the skewness of the distributions. Three scales were computed, one for each target of violence (partner, child, nonfamily member). The scales accounted for both the frequency of the aggression and the relative seriousness of the three different aggressive acts. The logarithmic scales were computed by taking the log of the sum of the weighted items. To account for the seriousness of the acts, items were weighted by the inverse of their relative frequency. The relative frequency was calculated by city, giving the same weight to each gender. To avoid extreme values, the median of the eight cities was used as the weight. All analyses were done using SPSS-PC software (SPSS Inc., Chicago, IL).

\section{RESULTS}

\section{Aggressive behaviors across different targets and behavioral contexts}

The association between aggression against the partner and aggression against a nonfamily member was strong. On average among all the eight cities, hitting a nonfamily member increased the odds of hitting the partner by 7.2 times (range among cities: 2.7 to 14.8). In six of the eight cities, the association between aggression against the partner and aggression against a child was also strong. On average, hitting the partner increased the odds of hitting a child by 3.5 times (range among cities: 1.5 to 9.3 ). The association between hitting the child and hitting a nonfamily member was weaker and statistically nonsignificant for all cities except Rio de Janeiro. All associations were stronger in Rio de Janeiro than in any other city. These results are based on a small sample, since the overall prevalence of having hit two or more persons (child, partner, nonfamily member) was low, less than $5 \%$ in half of the cities (Table 3 ).

Within each target group, aggressive behaviors were organized in a clear hierarchy of violence. Highly aggressive behaviors were less frequent than less aggressive behaviors, e.g., physical aggression was less frequent than verbal aggression. Those who reported the strongest form of aggression (hitting with an object) also reported the other forms of aggression, but not all who reported verbal aggression reported physical aggression. Fewer than $2 \%$ of the sample respondents reported they never insulted a nonfamily member but did threaten to hit one (range among cities: $0.9 \%$ to $2.7 \%$ ) or that they did hit a stranger but never threatened one (range among cities: $0.9 \%$ to $3.7 \%$ ). Fewer than $1 \%$ of the respondents reported they never shouted at the partner but did slap that person (range among cities: $0.1 \%$ to $0.9 \%$ ) or that they did hit the partner but never slapped him or her (range among cities: $0.3 \%$ to $3.4 \%$ ). Fewer than $5 \%$ of the sample reported that they never shouted at a child but did spank the child (range among cities: $1.2 \%$ to $7.3 \%$ ), and approximately $2 \%$ of the sample hit the child with an object but did not spank him or her (range among cities: $0.4 \%$ to $4.3 \%$ ).

\section{Physical aggression against nonfamily members}

On average, $6.5 \%$ of the men and $2.8 \%$ of the women hit a nonfamily member during the year prior to the study. The prevalence of hitting a nonfamily member was higher for men than women in all cities, but this difference did not achieve statistical significance in Rio de Janeiro or in Santiago (Table 3). Among those who did hit a nonfamily member, the mean number of times they hit did not vary significantly by the gender of the hitter. The highest reported prevalence of hitting nonfamily members was observed among men in Caracas, Cali, and Salvador.

As expected, physical aggression against nonfamily members was significantly higher among younger than older adults in all cities. The age group between 18 and 24 years old made up $21 \%$ of the total sample and accounted for $42 \%$ of the hitting of nonfamily members.

The relationship between educational level and aggression was confounded by age, since those with the lowest education (elementary education or less) were significantly older than those more educated. Among the youngest group (18-24 years old), prevalence of physical aggression toward nonfamily members was higher among those with low education than those with high education in Salvador, Cali, Caracas, and Madrid, but this difference achieved statistical significance only in Madrid. Among those 25 and older, aggression toward nonfamily members was not associated with educational level.

In all cities, prevalence of physical aggression toward nonfamily members significantly increased as the frequency of binge drinking increased. In addition, prevalence of physical aggression 
TABLE 3. Prevalence of physically aggressive behaviors by type, gender, target of violence, and city, ACTIVA project, 1997

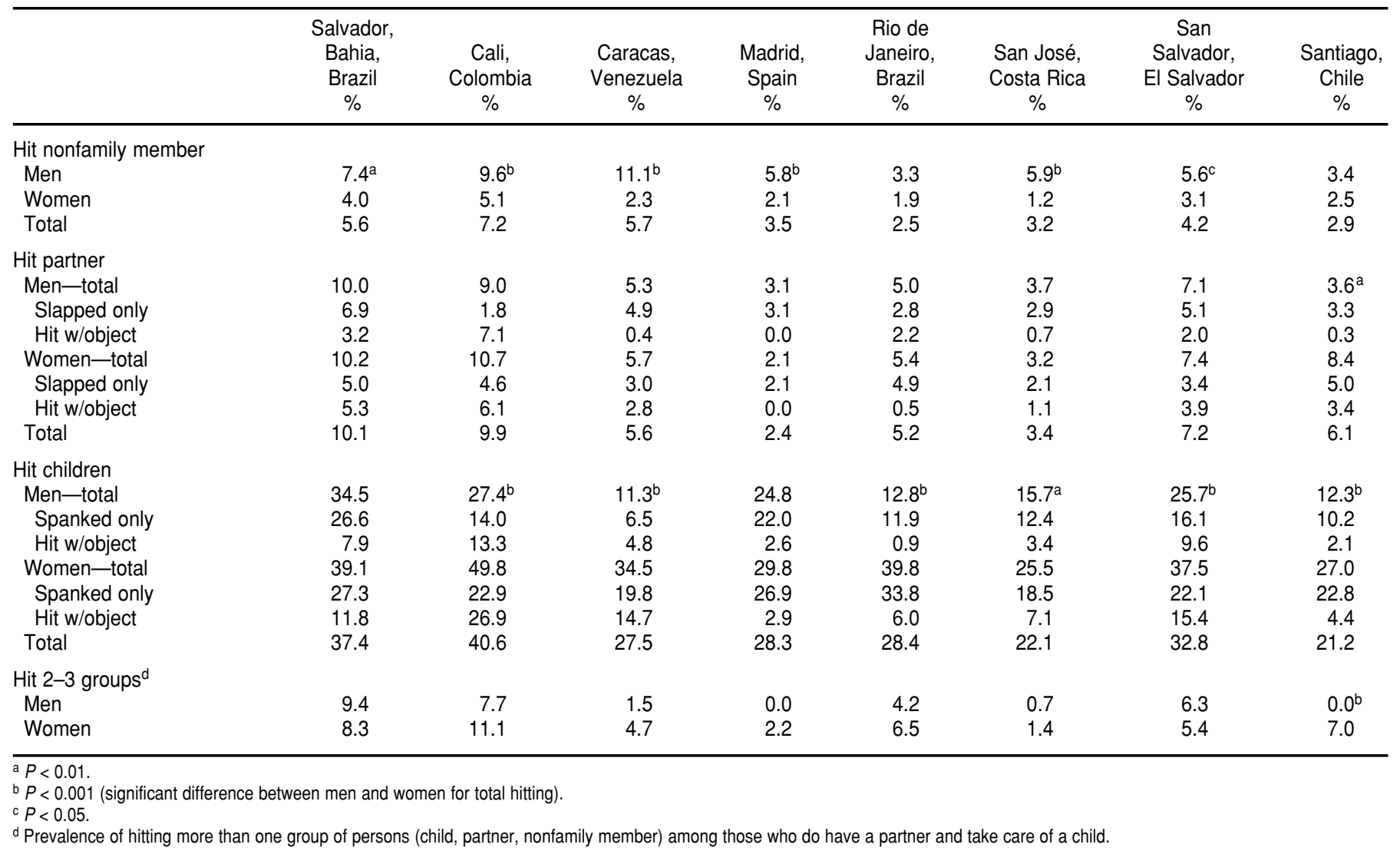

was higher among those who had or wanted to have a firearm, perceived the efficiency of the police as "very bad" or "bad," and preferred dictatorship over democracy. Not all differences were statistically significant.

In most cities, respondents who reported hitting a nonfamily member were more likely to hold attitudes that support violence and to have low selfefficacy for alternatives to violence. Cities where men expressed the strongest support for taking the law into their own hands also had the highest prevalence of hitting a nonfamily member (Pearson's $r=0.55$ ) and the strongest perception that the police were inefficient (Pearson's $r=$ $0.77)$. No association was found among the women surveyed.

In the regression model, the variance explained by attitudes and selfefficacy ranged from a low of $7 \%$ in Santiago to a high of $19 \%$ in Salvador and Cali. The overall model explained an average of $19 \%$ of the total variance (range among cities: $13 \%$ to $28 \%$ ). The variables with a stronger association with aggression toward a nonfamily member in all cities were lack of selfefficacy for alternatives to violence, frequency of binge drinking, being young and male, and holding an attitude that killing others was acceptable. In all cities, the lack of self-efficacy was one of the variables most strongly associated with aggression. The addition of behavioral and demographic variables doubled the predictive power of the model in Caracas, Rio de Janeiro, San José, and Santiago, and tripled it in Madrid.

\section{Physical aggression against the partner}

On average, $3.8 \%$ of the sample reported slapping their partner (but not hitting with an object) and $2.4 \%$ had hit their partner with an object during the year prior to the study. Most of those who hit with an object also slapped their partner. No statistically significant differences were observed by gender, except in Santiago, where women reported more frequently than men that they slapped or hit their male partners (Table 3). Among those who did hit their partner, the mean number of times women hit was significantly higher than for men in only one city, Salvador. The prevalence of partner battering was highest in Cali and Salvador, for both men and women.

Physical aggression toward the partner was more common among younger than older adults. Persons between 18 and 24 years old who had a partner accounted for $8 \%$ of the total sample but reported $19 \%$ of partner battering.

Physical aggression toward the partner was higher among respondents who reported binge drinking one or more times during the month prior to 
the survey. Physical aggression was also higher among respondents who wanted to have a firearm than among those who did not have a firearm. In most cities, the association between attitudes toward the environment and reported aggression was nonsignificant. However, in most cities, respondents who reported hitting the partner were significantly more likely to hold attitudes that support violence against the partner and to have low self-efficacy for alternatives to violence than respondents who did not hit their partner.

In the regression model, the variance explained by attitudes and selfefficacy ranged from $6 \%$ in San Salvador to $16 \%$ in Rio de Janeiro and Santiago. These same cities had the lowest and the highest percentage of variance explained by the overall model, respectively. The overall model explained an average of $15 \%$ of the total variance (range among cities: $8 \%$ to $21 \%$ ). The variables with a stronger association with aggression toward the partner in all cities were lack of self-efficacy for alternatives to violence, being young, and holding an attitude that slapping or hitting the partner was acceptable. In all cities, the lack of self-efficacy was one of the variables most strongly associated with aggression. The addition of behavioral variables that facilitate aggression did not improve the model significantly, except for Cali, where binge drinking and wanting to have a firearm improved the model by $36 \%$. In Caracas, Madrid, Rio de Janeiro, and Santiago the addition of demographic variables improved the model by a third.

\section{Physical aggression against children}

The prevalence of corporal punishment to discipline children was high. Among men, on average, 15\% had spanked a child (but did not hit with an object), and $6 \%$ had hit a child with an object during the month prior to the survey. Among women, on average, $24 \%$ had spanked a child (but did not hit with an object) and 11\% had hit a child with an object during the month prior to the survey. Most of those who hit with an object also spanked their children. No significant differences in corporal punishment were observed by gender except in Salvador and Madrid. In the six other cities, women were more likely than men to use corporal punishment with their children (Table 3). Both among men and women, the highest frequency of reported corporal punishment was among those who did not work outside the home. Among respondents who did hit their children, the mean number of times they hit was significantly higher among women than men in Cali, San José, and San Salvador. Although both men and women reported hitting boys more frequently than girls, this difference did not achieve statistical significance in any city. The overall prevalence of corporal punishment was over 30\% in Cali, Salvador, and San Salvador. Corporal punishment, however, did vary greatly by the age of the child. In all cities, children 2 to 7 years of age were those most frequently hit by their caretakers, with an average prevalence of $40 \%$. The highest peak was at ages 3 to 5 . The prevalence slowly declined as the child got older, being less than $20 \%$

\section{FIGURE 1. Prevalence of hitting children ${ }^{\mathrm{a}}$ and attitudes toward corporal punishment, ${ }^{\mathrm{b}}$ by city, ACTIVA project, 1997}

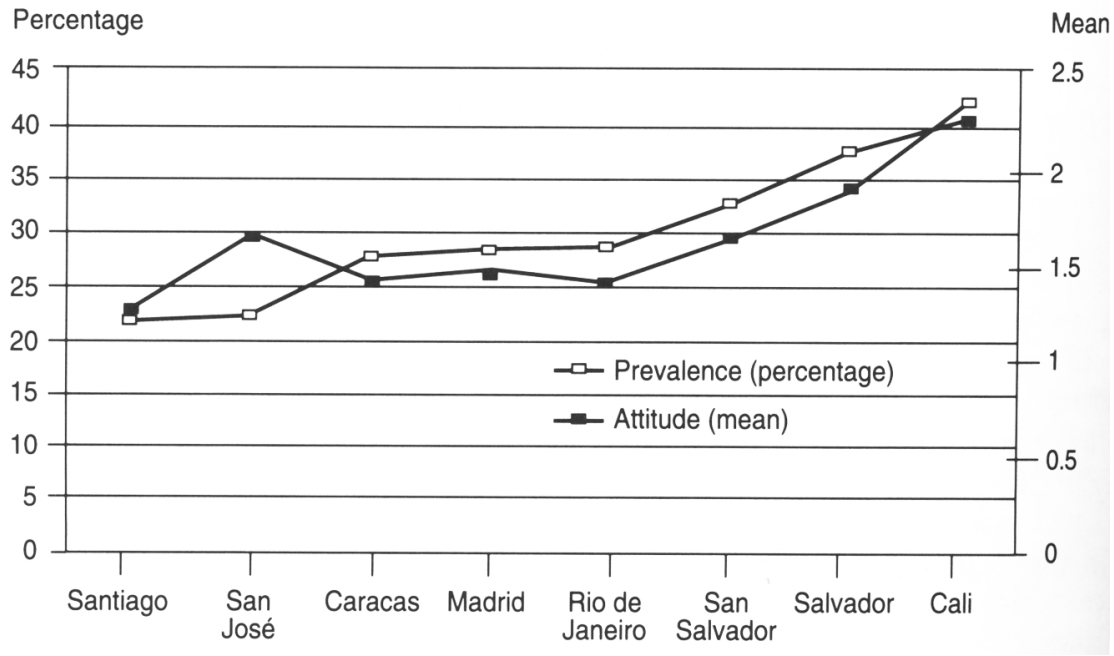

a Prevalence of hitting children during the month preceding the survey.

${ }^{\mathrm{b}}$ Attitude supporting corporal punishment on a scale from 1 (strongly disagree) to 5 (strongly agree). 
(range among cities: $12 \%$ to $25 \%$ ). The variables with a stronger association with aggression toward children in most cities were being young and female, having limited education, taking care of young children, lacking selfefficacy for alternatives to violence, and holding an attitude that corporal punishment was necessary. The addition of behavioral variables that facilitate aggression did not improve the model. The demographic variables, however, did increase the predictive power of the model. In Cali, Caracas, Rio de Janeiro, San José, and San Salvador, the addition of demographic variables doubled the percentage of variance explained by the model.

A final question that needs to be addressed concerns the characteristics of the people who reported hitting someone in more than one group. Given the small sample size of this group and its uneven distribution across cities, the data should be analyzed with caution. Thus, only some trends are reported. In comparison to those who reported hitting only one target, persons who reported hitting two or more groups were younger, less educated, more likely to be inebriated, had stronger attitudes toward specific behaviors supporting violence, showed a higher support for dictatorship, and had less self-efficacy for alternatives to violence.

\section{DISCUSSION}

In all cities, lack of self-efficacy for alternatives to violence was strongly associated with all forms of violence, that is, people who reported using aggression were less likely to feel confident that they could solve conflicts without violence. In addition and as expected, some attitudes toward specific behaviors were also associated with aggression. For example, the attitude that corporal punishment was necessary to rear a child was associated with aggression toward the child, and attitudes that supported slapping the spouse were associated with aggression toward the partner.

The overall model explained onefifth of the variance of aggression to- ward nonfamily members and somewhat less variance of aggression toward the family. Given that violence is determined by multiple factors and that this model evaluated only certain psychosocial components, the percentage of variance explained is good. In addition, the model supports a "dose effect," that is, those who aggress harder, more frequently, or to more than one target were more likely to hold stronger attitudes supporting violence and to have less self-efficacy to solve conflicts.

It is important to acknowledge some of the limitations of the study. First, the cross-sectional nature of the study does not allow for establishing a causative relationship between attitudes, self-efficacy, and aggressive behaviors. Second, additional limitations arise from the household interview methodology employed in this study, which may have increased socially desirable responses. Thus, the prevalence of aggressive behaviors and attitudes that support violence may be underreported. The prevalence found may also be lower than actual levels since the most violent or prejudiced persons may be the least likely to participate in this type of survey. Finally, this study only looked at some determinants of aggression. These results should be viewed in combination with other studies that address aspects of violence not addressed by the ACTIVA project, such as structural violence.

Aggressive behaviors were clearly ordered in a continuum that ranged from verbal aggression to hitting with an object. A large number of people reported verbal aggression, while fewer reported physical aggression. Those who did aggress physically also reported using milder forms of aggression. This result is consistent with other research that indicates a hierarchical progression of aggressive behaviors, in which an individual, over time, can progress from mild to serious forms of aggression (48). The concept of early prevention is supported not only by this continuum of aggressive behaviors but also by the growing evidence that verbal aggression can have permanent negative psychological consequences (49).

The prevalence of violence varied greatly by city. The prevalence of all forms of violence was highest in Cali, Salvador, and San Salvador, and was lowest in Madrid, Santiago, San José, and Rio de Janeiro. Caracas had a high prevalence of violence against nonfamily members by men, while violence against the family was lower. The cities with the highest reported frequency of violence also had the highest homicide rates. For example in 1996, the homicide rate for Cali was 102 per 100000 and for San Salvador was 140 per 100000 , while the homicide rate for Santiago was only 6 per 100000 and for Madrid was 2.2 per 100 000. The results from Rio de Janeiro are surprising. This city has a high homicide rate (80 per 100000$)$, while the reported frequency of hitting nonfamily members was the lowest of all cities. This result needs further investigation. One hypothesis is that homicides in the city are concentrated among a small group of people involved in drug trafficking and other forms of delinquency, rather than the less-aggressive general population.

The variables associated with aggression toward nonfamily members were not surprising: young men who reported binge drinking, held attitudes that support violence, and had low self-efficacy for alternatives to violence. Similar predictors of homicide have been found in the United States, where homicide is most frequent among young men who have been drinking alcohol and become involved in an argument (which can be a reflection of low self-efficacy to solve conflicts). However, one more component must be added to this equation to transform a dispute into a deadly event: a firearm. Those who reported hitting others were significantly more likely to either carry a gun or, if they did not have one, they would have liked to carry a firearm. In some cities, those who hit their partner were also more likely to want a firearm. Therefore, those who would like to carry a gun were not a random sample of the population. Important policy implica- 
tions for control of firearms derive from these results. Countries should have strict laws that limit the access to and the availability of guns. Results also indicate the need to evaluate the effect of policies and community education to reduce and control the consumption of alcohol, especially among young people.

The perception of poor police efficiency was associated with aggression against nonfamily members in four cities: Salvador, Cali, Rio de Janeiro, and San Salvador. All of them except Rio de Janeiro also had a high prevalence of reported violence. Cities with the highest prevalence of male aggression toward nonfamily members also showed the strongest support for people taking the law into their own hands and the strongest perception that the police system was inefficient. This association was not found among women, possibly because women are less likely to hit nonfamily members or to take the law into their own hands. When people do not trust the police system or perceive that the police will not protect them, they may be more likely to take justice into their own hands. The trust in the police system was not related to family violence. Rather than a criminal act, family violence is still considered by many a private matter that must be resolved without the help of the police. Thus, the police might not be perceived as having an important influence on whether or not violence is committed in the family.

The prevalence of violence against women by their male partner and violence against men by their female partner was remarkably similar. Similar results have been found in large prevalence studies in the United States (50). On average, $6 \%$ of the ACTIVA respondents reported having hit their partner at least once during the year prior to the survey. Although lower than in the United States (50), this estimated prevalence leaves little doubt about the high frequency of violence that both men and women commit against the partner. The fact that women are so violent within the family is inconsistent with the low rate of assaults by women outside of the family. Thus, the meaning and consequences of woman-to-man violence must be understood in the context of the relationship. Given that on average men are bigger and stronger than women and, in general, more aggressive, the same act (e.g., hitting with an object) is more likely to inflict pain and more likely to result in injury when it is inflicted by a man. Many of the assaults by women against a partner may be acts of retaliation or selfdefense. Supporting this is the fact that women are at higher risk of being killed by their partner than by a stranger (51). In all eight of the cities, physical aggression against the partner was associated with being young, having low self-efficacy for alternatives to violence, and holding attitudes that support violence. Thus, a possible avenue for prevention is to modify social norms that support violence and to increase skills for alternatives to violence. Future research should include questions about injury due to family violence to assess the seriousness of the problem, as well as questions about the context of the conflict.

Of special concern is the high prevalence of corporal punishment, especially hitting children with an object, which could be considered a form of child abuse. The highest prevalence was in Cali, where over one-fourth of the women reported hitting children with an object. Hitting children with an object was also high in Salvador, San Salvador, and Caracas, the same cities with high violence against nonfamily members and with high homicide rates. Since violence against children perpetuates the cycle of violence and may increase antisocial behavior (49), reducing corporal punishment may be an important avenue for violence prevention.

Corporal punishment was most common among young, uneducated women who held attitudes that corporal punishment was a way to discipline children and who had low selfefficacy to solve conflicts without violence. Interestingly, cities with the highest prevalence of aggression toward children also had the strongest attitudes supporting corporal punishment. Using corporal punishment to discipline children was most common among those who did housework, that is, did not work outside the home. Since $37 \%$ of the women and fewer than $2 \%$ of the men reported doing housework, the most likely explanation for women reporting using corporal punishment more frequently than men is simply that women are more likely to spend more time with their children at home. Although women reported hitting their children more frequently than men, the reported prevalence of men hitting children was still high. In addition, men may be more likely to hit their children harder than women. Thus, both men and women should be the focus of prevention programs that increase selfefficacy for disciplining children without the use of corporal punishment and that reduce attitudes that support corporal punishment. The high prevalence of corporal punishment among parents of young children gives some indication of the type of skills that caretakers lack for raising children.

The findings of the ACTIVA project are especially promising for the development of violence prevention interventions. Additional studies need to be done in each country to describe more specific attitudes associated with aggression within each subculture. Future programs to prevent and reduce aggression could focus on such activities as modifying attitudes that support violence, increasing self-efficacy for solving problems without violence, supporting development of an efficient police system that people can trust, regulating firearms and access to alcohol, and increasing people's education levels. 


\section{REFERENCES}

1. Koop CE, Lundberg GD. Violence in America: a public health emergency. JAMA 1992 Jun 10;267(22):3075-3076.

2. Mercy JA, Rosenberg ML, Powell KE, Broome $\mathrm{CV}$, Roper WL. Public health policy for preventing violence. Health Aff (Millwood) 1993 Winter;12(4):7-29.

3. Kreps GL, Kunimoto EN. Effective communication in multi-cultural health care settings. Thousand Oaks, CA: Sage; 1994.

4. Straus MA. Discipline and deviance: physical punishment of children and violence and other crime in adulthood. Social Problems 1991;38:133-153.

5. Murray B. Judges, courts get tough on spanking. A.P.A. Monitor 1996;27(11):10.

6. Krugman S, Mata L, Krugman R. Sexual abuse and corporal punishment during childhood: a pilot retrospective survey of university students in Costa Rica. Pediatrics 1992; 90:157-161.

7. Farrington DP. Early predictors of adolescent aggression and adult violence. Violence and Victims 1989;4:79-100.

8. Loeber R, Dishion TJ. Early predictors of male delinquency: a review. Psychol Bull 1983;94: 68-99.

9. Straus MA. Beating the devil out of them: corporal punishment in American families. New York: Cambridge University Press; 1994.

10. Straus MA. Spanking and the making of a violent society. Pediatrics 1997;98:837-841.

11. Straus MA, Sugarman DB, Giles-Sims J. Spanking by parents and subsequent antisocial behavior of children. Arch Pediatr Adolescent Med 1997;151:761-767.

12. Levav I, Guerrero R, Phebo L, et al. A regional effort to reduce corporal punishment in children: the promotion of a community program through primary care. Washington, D.C.: Pan American Health Organization/World Health Organization; 1995. (Document PAHO/WHO/ $\mathrm{HPP} / 45.95)$.

13. Heise LL, Pitanguy J, Germain A. Violence against women: the hidden health burden. Washington, D.C.: World Bank; 1994. (World Bank Discussion Paper No. 255).

14. Plichta S. The effects of woman abuse on health care utilization and health status: a literature review. Womens Health Issues 1992 Fall;2(3):154-163.

15. Physical violence during the 12 months preceding childbirth-Alaska, Maine, Oklahoma, and West Virginia, 1990-1991. MMWR Morb Mortal Wkly Rep 1994 Mar 4;43(8):132-137.

16. McFarlane J, Christoffel K, Miller V, Bullock L. Assessing for abuse: self-report versus nurse interview. Public Health Nurs 1991 Dec;8(4):245-250.

17. McFarlane J, Parker B, Soeken K, Bullock L. Assessing abuse during pregnancy: severity and frequency of injuries and associated entry into prenatal care. JAMA 1992;267:3176-3178.

18. Maguire K, Pastore AL. Sourcebook of criminal justice statistics, 1996. Washington, D.C.: U.S. Department of Justice; 1997. (Bureau of
Justice Statistics Overview Report NCJ165361)

19. Green LW, Kreuter MW. Health promotion planning: an educational and environmental approach. 2nd ed. Mountain View, CA: Mayfield Publishing Company; 1991. p. 429.

20. Bandura A. Social foundations of thought and action: a social cognitive theory. Englewood Cliffs, NJ: Prentice-Hall; 1986.

21. Bandura A. Aggression: a social learning analysis. Englewood Cliffs, NJ: Prentice-Hall; 1973.

22. Donnerstein E, Slaby RG, Eron LD. The mass media and youth aggression. In: Eron LD, Gentry JH, Schlegel P, eds. Reasons to hope: a psychosocial perspective on violence and youth. Washington, D.C.: American Psychological Association; 1996. p. 219-250.

23. Nisbett RE. Violence and U.S. regional culture. Am Psychol 1993;48:441-449.

24. Chassin $\mathrm{BH}$. Inequality and violence in the United States: casualties of capitalism. New Brunswick, NJ: Humanities Press; 1997.

25. Aronson E, Wilson TD, Akert RM. Social psychology: the heart and the mind. New York HarperCollins College Publishers; 1994.

26. Boldizar JP, Perry DG, Perry LC. Outcome values and aggression. Child Development 1989:60:571-579.

27. Guerra NG, Slaby RG. Evaluative factors in social problem solving by aggressive boys. J Abnormal Child Psychol 1989;17:277-289.

28. Slaby RG, Guerra NG. Cognitive mediators of aggression in adolescent offenders: 1 . assessment. Developmental Psychol 1988;24: 580-588.

29. Neel RS, Jenkins ZN, Meadows N. Social problem-solving behaviors and aggression in young children: a descriptive observational study. Behavioral Disorders 1990;16: 39-51.

30. Perry DG, Perry LC, Rasmussen P. Cognitive social learning mediators of aggression. Child Dev 1986 Jun;57(3):700-711.

31. Buka S, Earls F. Early determinants of delinquency and violence. Health Affairs 1993;12: 46-64.

32. DiLalla LF, Gottesman II. Biological and genetic contributors to violence-Widom's untold tale. Psychol Bull 1991;109:435-442.

33. Webster DW, Gainer PS, Champion HR. Weapon carrying among inner-city junior high school students: defensive behavior vs. aggressive delinquency. Am J Public Health 1993 Nov;83(11):1604-1608.

34. Callahan CM, Rivara FP. Urban high school youth and handguns. JAMA 1992;267:30383042.

35. Saltzman LE, Mercy JA, O'Carroll PW, Rosenberg ML, Rhodes PH. Weapon involvement and injury outcomes in family and intimate assaults. JAMA 1992;267:3043-3047.

36. Rice DP, MacKenzie EJ, and Associates. Cost of injury in the United States: a report to Congress. San Francisco, CA: Institute for Age and Aging of the University of California, and In- jury Prevention Center, The Johns Hopkins University; 1989

37. Kingery PM, Pruitt BE, Hurley RS. Violence and illegal drug use among adolescents: evidence from the U.S. National Adolescent Student Health Survey. Int J Addictions 1992; 27:1445-1464.

38. U.S. Department of Justice. Drugs and crime facts, 1991. Rockville, MD: Drugs \& Crime Data Center \& Clearinghouse; 1992. (Publication NCJ-134371.)

39. Centers for Disease Control. HomicideUnited States. MMWR Morb Mortal Wkly Rep 1982 Nov 12;31(44):594, 600-602.

40. American Medical Association. Healthy Youth 2000: national health promotion and disease prevention objectives for adolescents. Chicago, IL: AMA, Department of Adolescent Health; 1990

41. National Center for Health Statistics. Report of final mortality statistics, 1995. Monthly Vital Stat Rep 1997:45:1-80.

42. U.S. Centers for Disease Control and Prevention. Weapon-carrying among high school students-United States, 1990. MMWR Morb Mortal Wkly Rep 1991 Oct 11;40(40):681-684.

43. U.S. Centers for Disease Control and Prevention. Physical fighting among high school students-United States, 1990. MMWR Morb Mortal Wkly Rep 1992 Feb 14;41(6):91-94.

44. Hyde JS. How large are gender differences in aggression? A developmental meta-analysis. Dev Psychol 1984;20:722-736.

45. Fournier M, de los Ríos R, Orpinas P, PiquetCarneiro P. Estudio Multicéntrico sobre Actitudes y Normas Culturales frente a la Violencia. Proyecto ACTIVA: metodología. Rev Panam Salud Publica 1999:5(4/5):223-232.

46. Straus MA. Measuring intrafamily conflict and violence: the Conflict Tactics (CT) scales. In Straus MA, Gelles RJ, eds. Physical violence in American families: risk factors and adaptations to violence in 8,145 families. New Brunswick, NJ: Transaction Publications; 1990. p. 29-47.

47. Powell-Griner E, Anderson JE, Murphy W. State and sex-specific prevalence of selected characteristics-Behavioral Risk Factor Surveillance System, 1994 and 1995. MMWR CDC Surveill Summ 1997 Aug 1;46(3):1-31.

48. Loeber R. Development and risk factors of juvenile antisocial behavior and delinquency. Clin Psychol Rev 1990;10:1-41.

49. Gelles RJ, Harrop JW. Verbal aggression by parents and psychosocial problems of children. Child Abuse Neglect 1991;15:223-238.

50. Straus MA, Gelles RJ. How violent are American families? Estimates from the National Family Violence Resurvey and other studies. In: Hotaling G, Finkelhor D, Kirkpatrick JT, Straus MA, eds. Family abuse and its consequences: new directions in research. Newbury Park, CA: Sage Publications; 1988.

51. Bachman R. Violence against women. Washington, D.C.: U.S. Department of Justice, Bureau of Justice Statistics; 1994. (Publication NCJ-145325.) 
RESUMEN El propósito principal de este trabajo es evaluar la fuerza de la asociación entre: 1) las conductas agresivas y 2) las actitudes y autoeficacia en torno a alternativas a la violencia en diferentes ciudades de la Región de las Américas y España. Los resultados

¿Quién es violento?: factores asociados con los comportamientos agresivos en América Latina y España se basaron en una encuesta domiciliaria transversal de una muestra de la población entre los 18 y 70 años de edad. La encuesta se efectuó en ocho áreas metropolitanas de América Latina y España: Río de Janeiro, Brasil; Salvador, Bahía, Brasil; Santiago, Chile; Cali, Colombia; San José, Costa Rica; San Salvador, El Salvador; Caracas, Venezuela y Madrid, España. Cada muestra, que se compuso de alrededor de 1200 encuestados por ciudad, se estratificó por conglomerados y fue proporcionada en cuanto a posición socioeconómica y densidad poblacional. En todas las ciudades y de todas las personas estudiadas que fueron blancos de agresión, las que notificaron haber sido agresivas fueron menos propensas a sentirse capaces de resolver conflictos sin recurrir a conductas agresivas, y más propensas a adoptar actitudes a favor del uso de la violencia. Las personas jóvenes también se inclinaron más a conducirse de manera agresiva contra todo tipo de persona que fue blanco de agresión. Por añadidura, la agresión hacia personas ajenas a la familia fue más frecuente entre hombres jóvenes que notificaron tener episodios de consumo excesivo de alcohol, que llevaban un arma de fuego o tenían el deseo de llevarla, o que sentían que la policía era ineficiente. Hacen falta estudios adicionales en cada país para describir actitudes más específicas en relación con la agresión en cada subcultura. Los futuros programas de prevención deberán concentrarse en modificar las actitudes que favorecen la violencia, aumentar la autoeficacia para resolver problemas sin recurrir a actos violentos, apoyar el desarrollo de un sistema policiaco que despierte la confianza del público, regular la compra de armas de fuego y el acceso a bebidas alcohólicas y mejorar el nivel educativo de la población. 